\title{
APPROACHES TOWARD LEARNING IN PHYSIOTHERAPY
}

\begin{abstract}
The aim of this study was to investigate the approaches toward learning of undergraduate Physiotherapy students in a PBL module to enhance facilitation of learning at the Stellenbosch University Division of Physiotherapy in South Africa. This quantitative, descriptive study utilized the Revised Two-factor Study Process Questionnaire (R-SPQ-2F) to evaluate the study cohorts' approaches toward learning in the module. Results of the data instruments were analysed statistically and discussed in a descriptive manner.

There were a statistically significant greater number of students who adopted a deep approach toward learning at the commencement of the academic year. Students showed a trend toward an increase in their intrinsic interest in the learning material as the module progressed.

Students in the Applied Physiotherapy Module (ATP) started to shift their focus from a surface learning approach to a deep learning approach. Further research is needed to determine the long-term changes in approach toward learning and the possible determinants of these changes. This can be done in conjunction with the implementation of quality assurance mechanisms for learning material and earlier preparation of students for the change in the learning environment.
\end{abstract}

KEY WORDS: PROBLEM-BASED LEARNING, PHYSIOTHERAPY, LEARNING APPROACHES.

\section{INTRODUCTION}

The use of Problem Based Learning $(\mathrm{PBL})$ is a viable instructional approach in the training of physiotherapists (Solomon, 2005). Research regarding approaches toward learning in PBL is however not as prevalent in physiotherapy as in medicine and nursing (Lewis et al 2009), (Saalu et al 2010). In the aforementioned fields, students often change their approach toward learning depending on the environment in which they find themselves (Groves, 2005; (Dolmans et al 2010). PBL as an instructional approach, lends itself to a self-directed, deep approach toward learning as it requires a high cognitive level of engagement by students (Loyens et al 2008). The question is however, does PBL as an instructional approach indeed affect the approach students

\section{Correspondence Author:}

L Keiller

Division of Physiotherapy

University of Stellenbosch

Faculty of Health Sciences

PO Box 19063,

Tygerberg, 7505,

South Africa;

Email: 1keiller@sun.ac.za have towards learning? If an institution can gain knowledge of the students' approaches toward learning, it could be beneficial to educational institutions as a means to inform curriculum innovation or to evaluate a new curricular approach.

We conducted research into the influence a PBL module have on the approaches towards learning undergraduate physiotherapy students have. Our research question was therefore: Does a PBL module have an effect on undergraduate physiotherapy students approaches toward learning?

\section{LITERATURE}

Within the physiotherapy students' academic environment at this institution, various learning theories are pertantly embedded within their curriculum in order to enhance learning. One such learning theory is that of Constructivism, which refers to how students learn through creating meaning from things and/or situations which they have been exposed to previously (Schunk 2004). Another theory which is applicable is that of Social Learning, in which learners gather information for learning based on social experiences (Torre et al 2006). PBL as an instructional method, attempt to include both of these learning theories. One of the main characteristics of PBL is that it emphasizes self-directed learning (SDL) which "demands discipline on the part of the students" (Moust et al 2007). The ATP module in the Physiotherapy Division allow students to ulitise their knowledge base and foster effective participation in a collaborative manner. This will potentially enable them to develop the afore-mentioned self-directed learning skills (Loyens et al 2006). SDL as a quality of PBL can therefore be seen as an advantage that can be gained from the decision to make use of PBL in the APT module.

PBL have a positive effect on students (clinical) skills, learning styles, retention of knowledge, enhanced integration and application of basic science concepts into clinical contexts, to name a few (Vernon and Blake, (1993) Groves (2005), (Moust et al 2005). Conversely, disadvantages of PBL include the fact that students may be unaccustomed to the high levels of responsibility, the effect on transfer between problem situations in a course and similar ones in real life, the assessment methods and the lack of expert facilitators Colliver (2000), Gijbels, Dochy et al (2005).

Recognising that this pedagogical approach has its advantages and dis- 
advantages, we also identified that it can stimulate students to process knowledge on a deep level (Loyens et al 2008).

\section{APPROACHES TOWARD LEARNING}

A deep approach toward learning is characterized by studying for real meaning and understanding (Greasley et al 2007). Students adopting this approach toward learning engage with the subject matter in a way which promotes real understanding (Ellis et al 2008). This is contrasted by a surface approach toward learning in which students study by means of reading to remember disjointed facts (Greasley et.al, 2007). Students adopting this approach rely on external regulation and concentrate on the surface features of the work they are required to engage with within their learning environment (Papinczak 2009).

Conducting research on approaches students have toward learning, can guide the assessment and teaching styles in a direction to encourage students to adopt more effective approaches (Greasley et al 2007).

\section{AIM OF THE STUDY}

This study aimed to identify the approach toward learning that this cohort of students were adopting, as it had not yet been determined in this environment.

\section{METHODS \\ Context of the Study}

The first and second years of the B.Sc. Physiotherapy degree at Stellenbosch University (SU) (South Africa) are comprised of a predominantly, though not exclusive, lecture-based approach to pedagogy. One of the modules in both the first and second year, namely, Physiotherapy Science (PTS), aims to equip students with the theoretical knowledge as well as technical skills which they are to use in their third and fourth year in the Clinical Physiotherapy module (CPT) and the Applied Physiotherapy (APT) module. In the CPT module, students are required to provide physiotherapeutic care to patients. The APT module was developed utilising a PBL approach in the third year and an Enquiry Based Learning (EBL) approach in the fourth year. This was done in order to bridge the gap between the basic theoretical modules in the first two years and the CPT module where these theories and practical techniques need to be applied. Students are thus exposed to entirely new forms of learning opportunities through this module. This could lead to frustration and dissatisfaction as students are required to make the transition from a traditional module based approach (where lecturing is the core mode of instruction), to a new approach half-way through their course (Choi et al 2009). This blended curriculum, with regard to the various instructional approaches in each year of the course, is illustrated in Table 1, identifying how the various modules overlap and in turn lead into each other.

In keeping with the SU teaching and learning policy which requires a student centered approach to teaching (SU Policy on Teaching and Learning, 2007), the Division of Physiotherapy adopts a hybrid-PBL approach. The hybrid approach used at SU refers to the fact that unlike pure PBL curricula, students in the APT are given guidance through practical classes and the provision of background learning resources

Table 1: Schematic representation of the 4 Phases of the Physiotherapy Curriculum at Stellenbosch University

\begin{tabular}{|c|c|c|c|c|}
\hline & $\begin{array}{l}\text { Phase } 1 \\
\text { Scientific } \\
\text { Basis }\end{array}$ & $\begin{array}{l}\text { Phase } 2 \\
\text { Intermediary }\end{array}$ & $\begin{array}{l}\text { Phase } 3 \\
\text { Application }\end{array}$ & $\begin{array}{l}\text { Phase } 4 \\
\text { Professional } \\
\text { Entry }\end{array}$ \\
\hline \multicolumn{5}{|c|}{$\begin{array}{l}\text { Interdisciplinary } \\
\text { Phase }\end{array}$} \\
\hline \multicolumn{5}{|l|}{ Psychology } \\
\hline \multicolumn{5}{|l|}{ Anatomy } \\
\hline \multicolumn{5}{|l|}{ Physiology } \\
\hline \multicolumn{5}{|l|}{ Pathology } \\
\hline \multicolumn{5}{|l|}{$\begin{array}{l}\text { Physiotherapy } \\
\text { Science (PTS) }\end{array}$} \\
\hline \multicolumn{5}{|l|}{$\begin{array}{l}\text { Clinical } \\
\text { Physiotherapy } \\
\text { (CPT) }\end{array}$} \\
\hline \multicolumn{5}{|l|}{$\begin{array}{l}\text { Research } \\
\text { Methodology } \\
\text { (RM) }\end{array}$} \\
\hline \multicolumn{5}{|l|}{$\begin{array}{l}\text { Applied } \\
\text { Physiotherapy } \\
\text { (APT) }\end{array}$} \\
\hline $\begin{array}{l}\text { Physiotherapy } \\
\text { Practice (PTP) }\end{array}$ & & & & \\
\hline
\end{tabular}

by the academic staff (Savery and Duffy (2001); (Moust et al 2007). This is preceded by a tutorial session in which students are presented with various cases/ problems relative to clinical situations and building on subject matter learnt in the previous years. Students are required to submit and present their summarized information on the learning outcomes relevant to the case as their learning material, during a feedback session. Students also formulate multiple choice questions based on everything they have learnt at that stage. Should students engage on a superficial level with the content sourced by them during the PBL cases, it could negatively impact on their management of patients in the clinical setting. Thus, students enrolled in the APT module should benefit in their academic and clinical domains from adopting a deep approach toward learning.

\section{STUDY METHODOLOGY}

This descriptive, quantitative study was conducted shortly after the $3^{\text {rd }}$ year students started with the APT module. The final data collection was conducted once the students had completed their first 
semester in the APT module. The aim was to investigate their approach toward learning at the inception of their involvement in a PBL learning environment and then again at a later date once they had become accustomed to the instructional approach.

Ethical clearance for the study was granted by the Ethics Committtee at Stellenbosch University and the Division of Physiotherapy. The students were invited to participate in the study by means of purposive sampling. The study population was the 3rd year class of 2010 at the Division of Physiotherapy. Following the signing of informed consent, each student was given a participant number to ensure anonymity in the data collection and analysis process. The students were assured that they could withdraw their consent at any stage during the research project.

The Revised Study Process Questionnaire (R-SPQ-2F) (Biggs et al 2001) which is a validated tool for determining whether or not a student has a deep or surface approach toward learning was used in this study. The outcome of the 20-item R-SPQ-2F allows the researcher to determine each students approach to learning and the motive and strategy for learning, with regard to that particular pedagogical approach (Biggs et al 2001 and Groves (2005).

Though primarily a descriptive study, the research lent itself to a statistical approach in its analysis of the data. Data from the R-SPQ-2F was entered into Microsoft Excel by the researcher and handed over to a statistician. The R-SPQ-2F data was then analyzed by the statistician who used the term "strategy" to describe the approaches toward learning in his analysis of the data. Deep and surface approaches, along with their sub-categories, were compared over the two time points using repeated measures mixed model ANOVA. Post hoc tests were conducted using Fisher least significant difference (LSD). Significant effects were judged on a $5 \%(p<0.05)$ level.

\section{RESULTS}

The responses of the R-SPQ-2F were scored and identified those students who could be classified as having a deep or

Table 2: Approaches toward learning at the beginning (February) and middle of the year(July)

\begin{tabular}{|l|l|l|l|l|}
\hline $\begin{array}{l}\text { Approach to } \\
\text { learning }\end{array}$ & \multicolumn{2}{l|}{ R-SPQ-2F February } & \multicolumn{2}{l|}{ R-SPQ-2F July } \\
\hline & Number & Percent & Number & Percent \\
\hline Surface Approach & 12 & 31.58 & 10 & 26.32 \\
\hline Deep Approach & 26 & 68.42 & 27 & 71.05 \\
\hline Equal scores & 0 & 0 & 1 & 2.63 \\
\hline
\end{tabular}

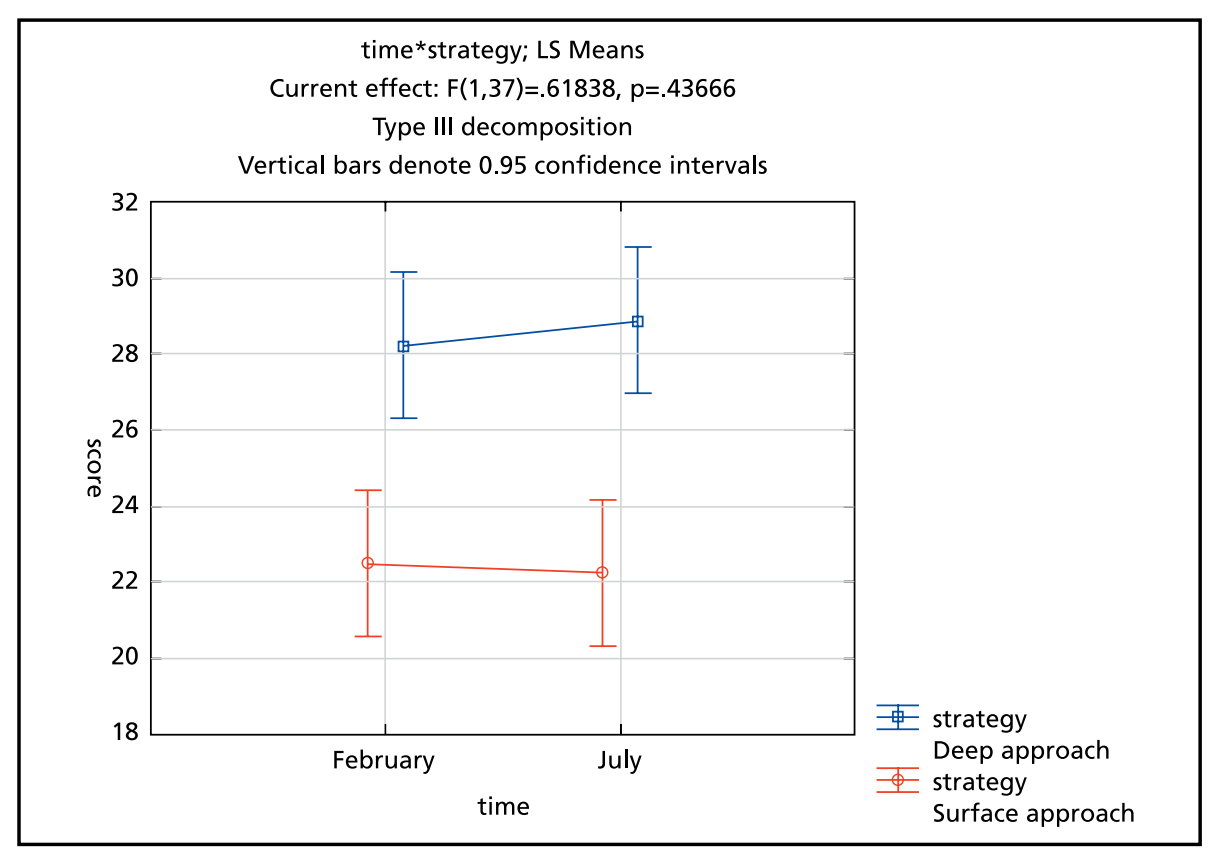

Figure 1: Deep versus Surface Approach over time

surface approach to learning. A response rate of $100 \%(n=38)$ was achieved for the R-SPQ-2F for both the beginning and end of the semester administration of the questionnaire. Table 2 identifies the percentage scores at the two time periods.

With a Cronbach alpha for the deep and surface approach were 0.85 and 0.79 respectively, the use of this instrument demonstrated acceptable reliability in this study.

At the first administration of the questionnaire there was a statistically significant difference in the number of students scoring higher in favour of the deep approach toward learning ( $p$-value: $<0.0078)$. The results of the questionnaire mid-way in the year continued to classify more students as having a deep approach toward learning than a surface approach (p-value: $<0.01)$. However, the comparison of the participants' scores at these two time intervals reveal no significant change in overall approach toward learning by the students from the start of their PBL environment experience to mid-way through that year. Figure 1 illustrates the comparative analysis of deep versus surface approach toward learning over the time period described above, with a no shift over time (p-value: 0.75 ).

The R-SPQ-2F identifies motives and strategies behind students approaches to learning. A distinction is made between having a deep or surface motive, as well as having either a deep or surface strategy to learning. The analyses of the results showed a trend toward a deep strategy being adopted by students participating in the study over the time period during which the study was conducted (Figure 2). This trend was, however, not significant, with a p-value of 0.05 . This trend was not seen in the results pertaining to the Deep versus Surface motives, with no shift seen at either the first or second administration of the R-SPQ-2F for both deep and surface motives (Figure 3). 


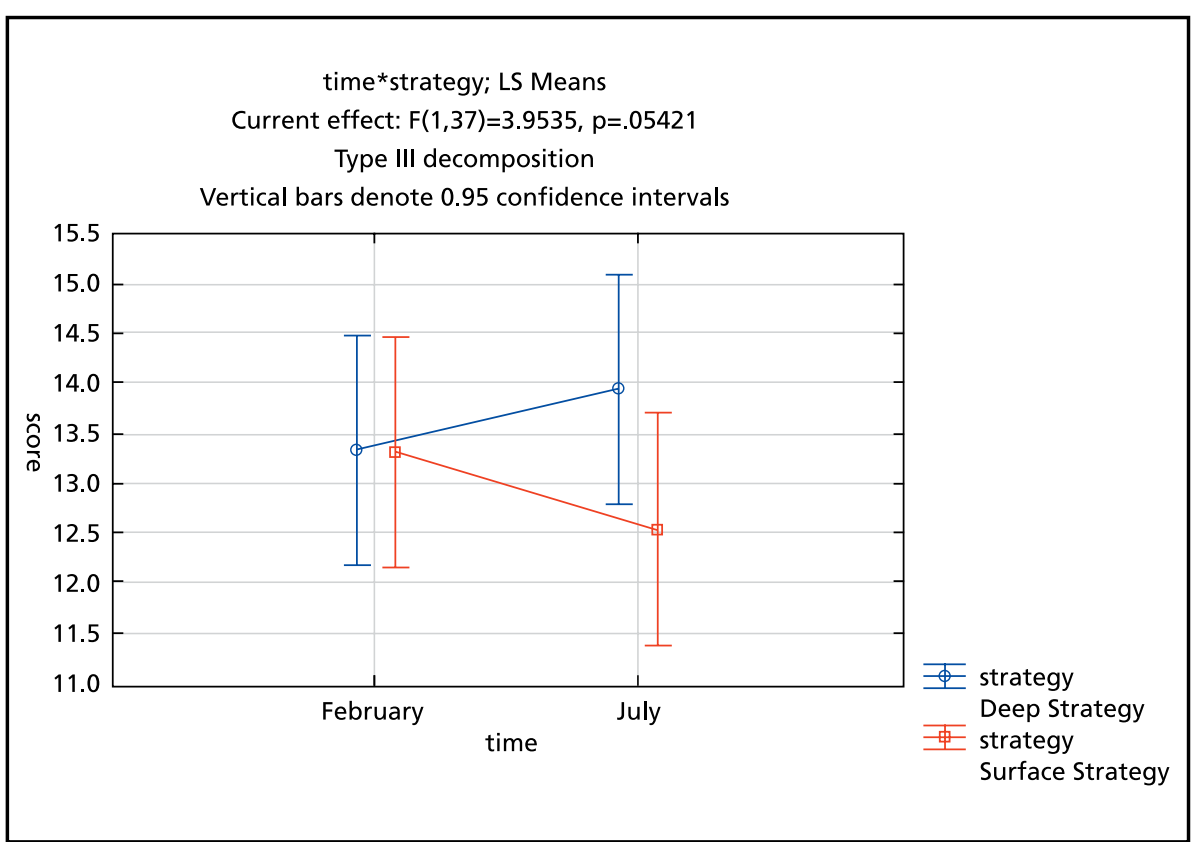

Figure 2 Deep versus Surface strategies over time

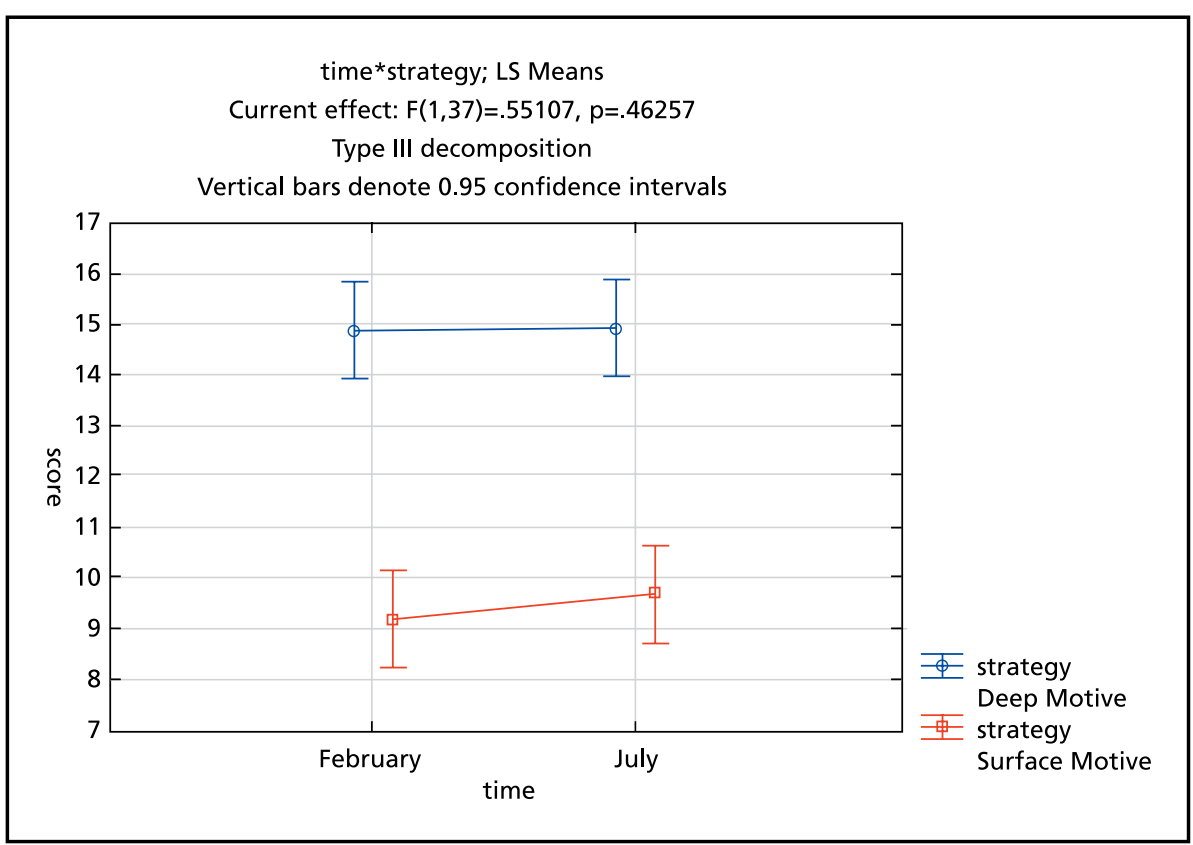

Figure 3 Deep versus Surface motives over time

Deep motive, however, measured significantly higher than surface motive, $\mathrm{p}$-value $<0.1$. These results are discussed further on in this article.

\section{DISCUSSION}

It was the intention of this study to investigate the approaches toward learning of $3^{\text {rd }}$ year students at a relatively early stage in their transition to a learning environment which forced them to take a greater responsibility for their own learning. This investigation would then allow academic staff to use the information for facilitation of learning.
Apart from identifying the students' approach to learning, the R-SPQ-2F identifies motives and strategies behind students approaches to learning. A student who has an intrinsic interest in the learning environment and materials is said to have a deep motive. Those who have a surface motive influencing their approach to learning are said to have a fear of failure (Kember et al 2004). These motives cannot, however, be viewed on a solely independent basis as the specific structure of the R-SPQ-2F requires a concurrent analyses of the strategies employed by students along with their motives. The strategies either related to a student's tendency to have a narrow target approach to learning materials and rote learning, or those who tend to approach a learning environment with a need to maximize meaning in that environment (Kember et al 2004).

Groves (2005) found that the learning environment is likely determine a student's approach toward learning more than the inherent traits of that student. The findings of this study indicate that students responded to the learning environment by starting to shift their focus from having a narrow target approach (focusing on lists of facts), in an attempt to maximize meaning of their experiences and learning in the module.

The inclination toward their motive being driven by fear of failure as opposed to an intrinsic interest in the learning material at the middle of the year, is cause for concern. The inherent approach to learning that students have at the beginning of the module, should however encourage staff to ensure that these students are maintaining their deep approach throughout the module. It is necessary to remember that students easily change from deep to surface or surface to deep approach depending on the assessment, learning outcomes or facilitator, among others (Kember et al (2004); (Groves 2005); (Greasley et al 2007); (Dolmans et al 2010).

Using the results optimally for the facilitation of student learning, will require the academic staff to make changes to the curriculum. It will also be necessary to conduct further research to ensure that these results are not specific to this particular cohort of students, but rather, transferrable to other groups of students in PBL environments.

To ensure that students continue to internalize information they come into contact with through the PBL sessions, in-depth discussion during feedback sessions should be encouraged and facilitated by staff members involved in cases. A recommendation for improving the feedback sessions, is to change the format in a way where student-initiated videos can be used. This can be done in combination with written descriptions allowing for role-playing with associated self-reflection on information for- 
mulated by students. This in turn could potentially facilitate a shift toward a deep approach to learning, as opposed to PBL cases in which students are simply reliant on group members to provide them with the information.

Understanding why and how students can have an inclination toward a deep approach toward learning and yet not significantly change their approach from surface to deep, could furthermore be clarified if a questionnaire such as the PBL-R-SPQ (a modified verson) could be used (Dolmans et al 2010). This will be useful for module refinement and curriculum planning. An addition to the current study, for future research, could be to investigate the assessment outcomes with the approaches toward learning of students in the APT module in order to identify any correlation between these factors and academic achievement. The results of which, over an extended period of time, would ensure enhanced facilitation of learning.

\section{CONCLUSION}

Within the profession of Physiotherapy, PBL remains a viable curricular option which needs to be further studied and debated Solomon (2005). As the Physiotherapy Division of SU decided on this approach for the APT module in 2007 as one which would help to develop the skills needed by students to be competent when working in the community (Statham et al 2008), the need to evaluate the module on various levels, including the transfer of knowledge between the classroom and community, remains pertinent to the continued refinement of the module. The concept of studying approaches to learning can guide the assessment and teaching styles in a direction to encourage students to adopt more effective approaches (Greasley et al 2007).

Though there was no significant change in approach toward learning in these students, alignment of assessment, learning outcomes, and teaching and learning activities is important to positively influence approaches toward learning in a PBL environment (Dolmans et al 2010). Therefore, further research in this environment is needed to ensure this alignment. Approaches toward learning are not necessarily a static phenomenon; rather, it varies as the learner is faced with different situations and expectations in a module. With this in mind, the Physiotherapy Division at SU are now able to build on this research to inform further curriculum refinement and development.

\section{ACKNOWLEDGEMENTS}

Alwyn Louw, Ph.D, M.Ed is the Extended Degree Program Coordinator at the Centre for Health Sciences Education in the Faculty of Health Sciences at Stellenbosch University. Dr. Louw is also a FAIMER fellow-2008.

\section{REFERENCES}

Ashworth P, Lucas U (2000) Achieving empathy and engagement: A practical approach to design, conduct and reporting of phenomenographic research. Studies in Higher Education 25: 295-308

Biggs J, Kember D, Leung DYP 2001 The revised two-factor study process questionnaire: R-SPQ-2F. British Journal of Educational Psychology 71: 133-149

Choi I, Lee SJ, Kang J 2009 Implementing a case-based e-learning environment in a lectureoriented anesthesiology class: Do learning styles matter in complex problem solving over time? British Journal of Educational Technology 40(5): 933-9479-70

Dolmans DHJM, Wolfhagen IHAP, Ginns P 2010 Measuring approaches to learning in a problem based learning context. International Journal of Medical Education 1: 55-60

Ellis RA, Goodyear P, Brilliant M, Prosser M 2008 Student experiences of problem-based learning in pharmacy: conceptions of learning, approaches to learning and the integration of face-to-face and on-line activities. Advances in Health Sciences Education 13:675-692

Gijbels D, Dochy F, van den Bossche P, Segers M 2005 Effects of Problem-Based Learning: A MetaAnalysis From the Angle of Assessment. Review of Educational Research 75 (1):27-61

Greasley K., Ashworth P 2007 The phenomenology of 'approach to studying': The university student's studies within the lifeworld. British Educational Research Journal 33(6):819 - 843

Groves M 2005 Problem-Based Learning and Learning Approach: Is There a Relationship? Advances in Health Sciences Education 10: 315-326
Kember D, Biggs J, Leung DYP 2004 Examining the multidimensionality of approaches to learning through the development of a revised version of the learning process questionnaire. British Journal of Educational Psychology 74:261-280

Leung M, Chan K 2001 Construct Validity and Psychometric Properties of the Revised Two-factor Study Process Questionnaire (R-SPQ-2F) in the Hong Kong Context. Australian Association for Research in Education, Perth, Australia Available at http://www.aare.edu.au/01pap/cha01708.htm [Accessed 24 August 2010]

Lewis $\mathrm{AD}$, Menezes DAB, McDermott HE, Hibbert LJ., Brennan SL, Ross EE, Jones LA 2009 A comparison of course-related stressors in undergraduate problem-based learning (PBL) versus non-PBL in medical programmes. BMC Medical Education 9: 60 Available at http:// www.biomedcentral.com/1472-6920/9/60 [Accessed May 2010]

Loyens SMM, Magda J, Rikers RMJP 2008 Selfdirected learning in problem-based learning and it's relationships with self-regulated learning. Educational Psychology Review 20:411-427

Moust JHC, Van Berkel HJM, Schmidt HG 2005 Signs of erosion: Reflections on three decades of problem-based learning at Maastricht University. Higher Education 50:665-683

Moust JHC, Bouhuijs PAJ, Schmidt HG 2007 Introduction to Problem-based learning. A guide for students.

Netherlands: Wolters-Noordhoff Publishers

Papinczak T 2009 Are deep strategic learners better suited to PBL? A preliminary study. Advances in Health Sciences Education 14: 337-353

Saalu LC, Abraham AA, Aina WO 2010 Quantitative evaluation of third year medical students' perception and satisfaction from problem based learning in anatomy: A pilot study of the introduction of problem based learning into the traditional didactic medical curriculum in Nigeria. Educational Research and Reviews 5(4):193-200 Available online at http://www.academicjournals. org/ERR [Accessed July 2010]

Schunk DH 2004 Learning theories. An educational perspective. $4^{\text {th }}$ Edition. New Jersey: Pearson Education Inc.

Solomon P 2005 Problem-based learning: a review of current issues relevant to physiotherapy education. Physiotherapy theory and practice 21(1):37-49

Torre DM, Daley BJ, Sebastian JL, Elnicki M 2006 Overview of current learning theories for medical educators. American Journal of Medicine 119 (10): 903-907 